\title{
Air Quality Implications of COVID-19 in California
}

\author{
Shuai Pan ${ }^{1,2, *}$, Jia Jung ${ }^{3}{ }^{\circledR}$, Zitian $\mathrm{Li}^{4}{ }^{4}$, Xuewei Hou ${ }^{1}$, Anirban Roy ${ }^{5}$, Yunsoo Choi ${ }^{3}$ and \\ H. Oliver Gao ${ }^{2, *}$ \\ 1 School of Atmospheric Physics, Nanjing University of Information Science and Technology (NUIST), \\ Nanjing 210044, China; houxw@nuist.edu.cn \\ 2 School of Civil and Environmental Engineering, Cornell University, Ithaca, NY 14853, USA \\ 3 Department of Earth and Atmospheric Sciences, University of Houston, Houston, TX 77204, USA; \\ helloiamjia@gmail.com (J.J.); ychoi6@uh.edu (Y.C.) \\ 4 Nanning Meteorological Service, Nanning 530000, China; lizit0408@163.com \\ 5 Independent Researcher, Sacramento, CA 95814, USA; anirban.roy0982@gmail.com \\ * Correspondence: sp694@cornell.edu (S.P.); hg55@cornell.edu (H.O.G.)
}

Received: 7 July 2020; Accepted: 27 August 2020; Published: 30 August 2020

\begin{abstract}
The COVID-19 pandemic has significantly affected human health and the economy. The implementation of social distancing practices to combat the virus spread, however, has led to a notable improvement in air quality. This study compared the surface air quality monitoring data from the United States Environmental Protection Agency (U.S. EPA)'s AirNow network during the period 20 March-5 May in 2020 to those in 2015-2019 from the Air Quality System (AQS) network over the state of California. The results indicated changes in fine particulate matter $\left(\mathrm{PM}_{2.5}\right)$ of $-2.04 \pm 1.57 \mu \mathrm{g} \mathrm{m}^{-3}$ and ozone of $-3.07 \pm 2.86 \mathrm{ppb}$. If the air quality improvements persist over a year, it could potentially lead to 3970-8900 prevented premature deaths annually (note: the estimates of prevented premature deaths have large uncertainties). Public transit demand showed dramatic declines $(\sim 80 \%)$. The pandemic provides an opportunity to exhibit how substantially human behavior could impact on air quality. To address both the pandemic and climate change issues, better strategies are needed to affect behavior, such as ensuring safer shared mobility, the higher adoption of telecommuting, automation in the freight sector, and cleaner energy transition.
\end{abstract}

Keywords: COVID-19; air quality; shared mobility; telecommuting; climate change

\section{Introduction}

The COVID-19 pandemic has caused enormous adverse impacts on human health and economy. To combat the virus spread, many regional and national governments have issued the stay-at-home orders in order to improve social distancing and minimize person-to-person contact. The implementation of such practices (including telecommuting), however, has led to notable improvements in air quality. Several studies have assessed the impacts of the stay-at-home orders on air quality in worldwide regions [1-5]. Generally, they reported reductions in concentrations of nitrogen dioxide $\left(\mathrm{NO}_{2}\right)$ and fine particulate matter $\left(\mathrm{PM}_{2.5}\right)$, and in some cases an increase in the ground-level ozone $\left(\mathrm{O}_{3}\right)[1,5]$. The satellite $\mathrm{NO}_{2}$ decreased by $40 \%$ over Chinese cities and $20-38 \%$ in Western Europe and the northeastern United States [2]. Elevated concentrations of air pollutants (e.g., $\mathrm{PM}_{2.5}$ and $\mathrm{O}_{3}$ ) can cause respiratory and cardiovascular problems, and even premature death [6-11]. Hence, a change in air quality due to the pandemic may potentially affect health outcomes.

To date, no similar detailed quantitative analysis has been conducted for the state of California. In California, the Greater Los Angeles Area (LA) and San Joaquin Valley (SJV) are classified as "Moderate" nonattainment areas for $\mathrm{PM}_{2.5}$, by the United States Environmental Protection Agency (U.S. EPA). Additionally, the LA, SJV, and San Francisco Bay Area (SF) are, respectively, classified as 
"Extreme", "Extreme", and "Marginal" nonattainment areas for $\mathrm{O}_{3}$ [12]. Thus, air quality issues are still a major concern in these areas. On 19 March 2020, the statewide stay-at-home order was implemented in California $[13,14]$. Since then, millions of residents have adjusted their travel behavior in accordance with the order. This creates a valuable opportunity to evaluate the impact of changing travel behavior or lockdown on air quality and the associated health effects. In this study, we investigate the change in air quality using measurements from surface monitoring stations operated by the U.S. EPA's AirNow [15] and Air Quality System (AQS) networks [16]. The AirNow network stores near-real-time air quality measurements, while AQS contains historical data that have undergone quality assurance and quality control. This study aims to answer the following questions:

(1) What are the magnitudes of changes in the regional $\mathrm{PM}_{2.5}$ and $\mathrm{O}_{3}$ concentrations during the pandemic time period?

(2) What are the magnitudes of $\mathrm{PM}_{2.5}$ - and $\mathrm{O}_{3}$-induced premature mortality? How could health outcomes vary across regions in California?

(3) How could transportation activity change due to the pandemic? What are the opportunities in attaining air quality improvement in the post-pandemic period?

\section{Materials and Methods}

\section{1. $\mathrm{PM}_{2.5}$ and $\mathrm{O}_{3}$ Air Quality Measurements and Episode Selection}

We obtained hourly surface air quality monitoring data in 2020 from the AirNow network [15], and those from five historical years (2015-2019) from the AQS network [16]. The AirNow observational data are collected using federal reference or equivalent monitoring methods approved by the U.S. EPA. Although the AirNow data have undergone preliminary data quality assessments, they are not subjected to the full validation required by AQS, the U.S. EPA's regulatory database. In order to ensure the data quality and consistency, we utilized measurement data from monitors that were reported in both AQS and AirNow. Chai et al. [17] compared the $\mathrm{O}_{3}$ measurements that were reported in both AQS and AirNow, and they showed a good agreement, with a correlation of more than 0.99 . A comprehensive literature review of recent publications on the performance of low-cost air sensors was provided by the U.S. EPA [18].

In this study, the following episodes were considered:

(1) 20 March-5 May, hereafter called Episode 1, or E1. E1 2020 was the time period when a state-wide lockdown was implemented in California. E1 2015-2019 was the corresponding historical time period with normal air quality conditions.

(2) 1 February-5 March, hereafter called Episode 2, or E2. The air quality in E2 2020 reflected the normal conditions in this year, before the lockdown was initiated. E2 2015-2019 represents the historical normal.

In California, there are 50 sites of $\mathrm{PM}_{2.5}$ measurements and $\sim 130$ sites of $\mathrm{O}_{3}$ measurements, reported in both AirNow and AQS. The exact same time periods, 20 March-5 May and 1 February-5 March, are used for all the years considered. We calculated the episode-average concentrations of $\mathrm{PM}_{2.5}$, the maximum daily $8 \mathrm{~h}$ average (MDA8) $\mathrm{O}_{3}$ for each study time period, and the difference (in both absolute value and percentage) between the 2020 average and the (2015-2019) historical average for each episode. The change in air quality during the lockdown time period (i.e., Episode 1) between 2020 and 2015-2019 could not be solely attributed to COVID-19. There are other potential contributing factors, such as meteorological variations and long-term emission changes. Thus, Episode 2, the pre-lockdown time period, can be used as a control and an uncertainty estimate. The change in air quality during Episode 2 could represent the variability between the normal conditions in this year and the averaged historical normal - that is, how much departure from average conditions one might expect in this year (although weather and its impact on air quality could be different between pre-lockdown and lockdown in 2020). 


\subsection{Air Quality Associated Health Impact Assessment}

To assess the potential air quality-associated health impact, we used the U.S. EPA Environmental Benefits Mapping and Analysis Program (BenMAP) Community Edition version 1.3 [19-21]. The concentration-response (C-R) functions are usually utilized to characterize the relationships between air pollution and human health; an increase in adverse health effects would coincide with an exacerbation of ambient air pollution concentrations. We used the log-linear format C-R functions:

$$
\Delta y=\left(1-e^{-\beta \cdot \Delta x}\right) \times y_{0} \times P o p,
$$

where $\Delta y$ represents the change in the incidence of adverse health effects, $\beta$ is the C-R coefficient, $\Delta x$ is the change in air quality, $y_{0}$ is the baseline incidence rate, and Pop is the affected population. The C-R relationships (i.e., $\beta$ ) are usually assessed in epidemiological studies. In this study, we mainly adopted the C-R relationships from Krewski et al. [6], Lepeule et al. [7], and Woodruff et al. [8] for the $\mathrm{PM}_{2.5}$-attributed mortality, and Bell et al. [9], Levy et al. [10], and Zanobetti and Schwartz [11] for the $\mathrm{O}_{3}$-attributed mortality, as recommended by the U.S. EPA [22,23]. More details about the C-R coefficients in epidemiological studies are listed in Table 1, as well as described in Pan et al. [24,25]. The stationary air quality measurements were interpolated to spatial fields using the Voronoi neighborhood averaging (VNA) method [23].

Table 1. The concentration-response functions for the $\mathrm{PM}_{2.5^{-}}$and $\mathrm{O}_{3}$-induced premature mortality used in this study.

\begin{tabular}{ccccc}
\hline Species & Epidemiological Reference & Risk Estimate, $\boldsymbol{\beta}$ & Age Range & Derived Locations \\
\hline \multirow{3}{*}{ PM $_{2.5}$} & Krewski et al. [6] & 0.00583 & $30-99$ & 116 U.S. cities \\
\cline { 2 - 5 } & Lepeule et al. [7] & 0.01310 & $25-99$ & 6 Eastern Cities \\
\cline { 2 - 5 } & Woodruff et al. [8] & 0.00392 & $0 ;$ infants & 86 cities \\
\cline { 2 - 5 } Ozone & Bell et al. [9] & 0.00079 & $0-99$ & US and non-US \\
\cline { 2 - 5 } & Levy et al. [10] & 0.00112 & $0-99$ & US and non-US \\
\cline { 2 - 5 } & Zanobetti and Schwartz [11] & 0.00051 & $0-99$ & 48 cities \\
\hline
\end{tabular}

\subsection{Miscellaneous Data: Public Transit Demand, Telecommuting Status, and Energy Mix}

We collected several datasets related to meteorology, passenger travel, transportation emissions, and energy use. Meteorological factors, temperature and wind speed, were obtained from the Automated Surface Observing System (ASOS) network (https://mesonet.agron.iastate.edu/ASOS/). Public transit demand data at two Californian metropolitan areas were obtained from one smartphone app-Transit app [26]. The commuting/telecommuting status data were from the 2018 American Community Survey (ACS) 5-year Estimates, Tables DP03 (selected economic characteristics) and B08126 (means of transportation to work by industry) [27]. The electricity generation resource mix data were from the Emissions and Generation Resource Integrated Database (eGRID), version from 2018 [28].

\section{Results and Discussion}

\subsection{Change in Air Quality during the "Stay-at-Home Order" Time Period}

Figure 1 plots the E1 (20 March-5 May) episode-average surface concentrations of $\mathrm{PM}_{2.5}$ and MDA8 $\mathrm{O}_{3}$. Compared to the E1 2015-2019 historical conditions in Figure 1a, the $\mathrm{PM}_{2.5}$ concentrations exhibit notable domain-wide reductions in E1 2020 in Figure 1b; the changes are $-2.04 \pm 1.57 \mu \mathrm{g} \mathrm{m}^{-3}$ in Figure $1 \mathrm{c}$ and $-27.25 \pm 23.88 \%$ in Figure $1 \mathrm{~d}$. There is an increase in $\mathrm{PM}_{2.5}$ in the east bay in Figure $1 \mathrm{c}, \mathrm{d}$, and the cause is not clear. The results for $\mathrm{MDA} 8 \mathrm{O}_{3}$ indicate widespread reductions between the five-year historical average in Figure 1e and the 2020 lockdown average in Figure 1f; the changes are $-3.07 \pm 2.86 \mathrm{ppb}$ in Figure $1 \mathrm{~g}$ and $-8.08 \pm 7.93 \%$ in Figure $1 \mathrm{~h}$. One exception is that the $\mathrm{O}_{3}$ increases in 
urban Los Angeles; this is to be expected, as the area has significant nitrogen oxide $\left(\mathrm{NO}_{\mathrm{x}}\right)$ emissions from transportation sources, and it is $\mathrm{NO}_{\mathrm{x}}$-saturated. Reductions in the $\mathrm{NO}_{\mathrm{x}}$ emissions due to the pandemic/lockdown could lead to a decreasing $\mathrm{NO}_{x}$ saturation (and hence $\mathrm{O}_{3}$ increase).
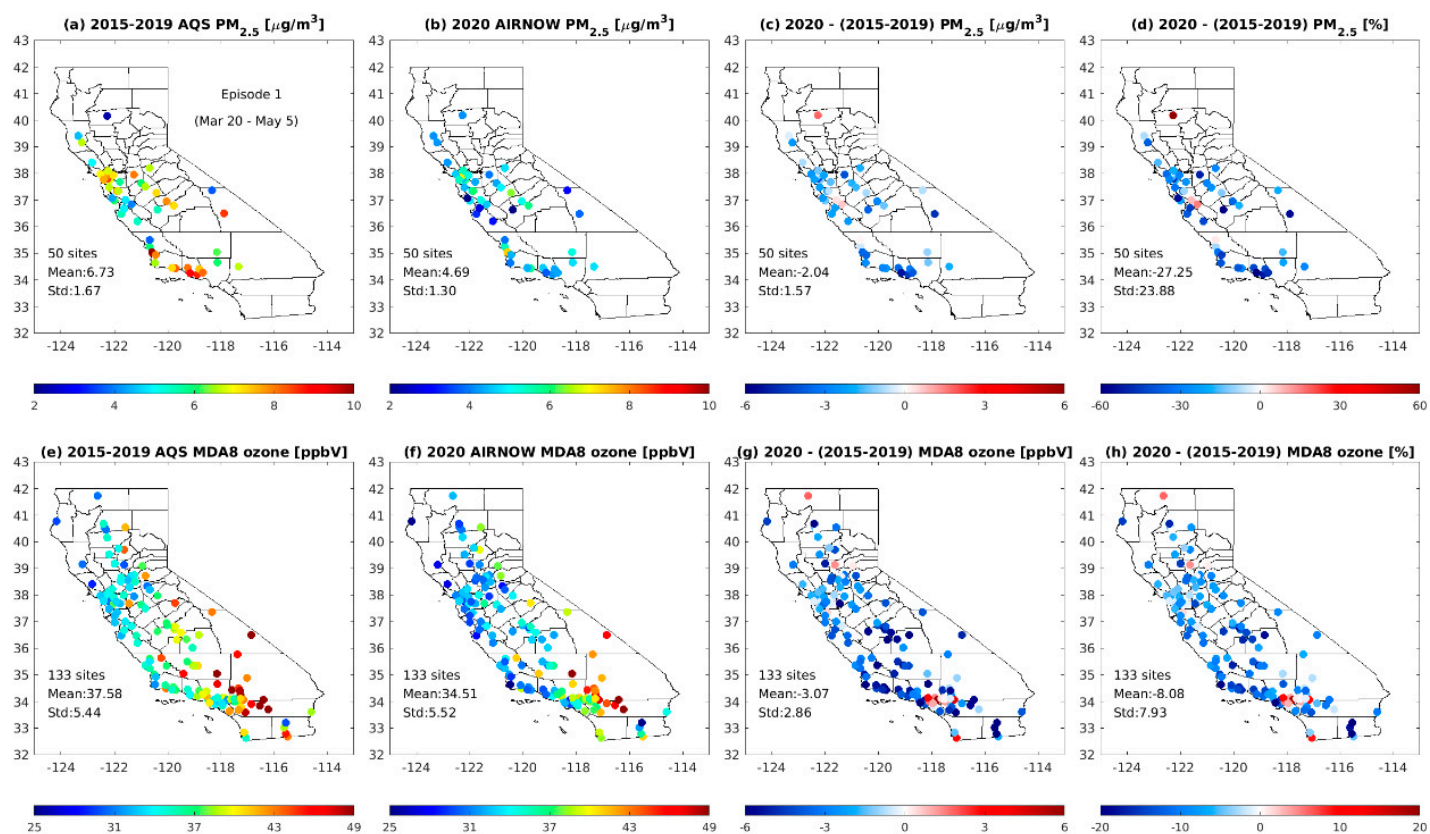

Figure 1. The Episode 1 (20 March-5 May) episode-average surface concentrations of $\mathrm{PM}_{2.5}$ and MDA8 $\mathrm{O}_{3}$ : (a) historical $\mathrm{PM}_{2.5}$, (b) lockdown $\mathrm{PM}_{2.5}$, (c) lockdown minus historical $\mathrm{PM}_{2.5}$, (d) similar to (c) but in percentage, (e) historical $\mathrm{MDA}_{8} \mathrm{O}_{3}$, (f) lockdown $\mathrm{MDA}_{8} \mathrm{O}_{3}$, (g) lockdown minus historical MDA8 $\mathrm{O}_{3}$, (h) similar to $(\mathbf{g})$ but in percentage. In each panel, the number of sites, mean, and standard deviation (Std) were provided.

Figure 2 plots the E2 (1 February-5 March) episode-average surface concentrations. The $\mathrm{PM}_{2.5}$ in E2 2015-2019 in Figure 2a and E2 2020 in Figure 2b show similar distribution patterns; the differences indicate a mixing of increase and decrease in Figure $2 \mathrm{c}, \mathrm{d}$. The differences for MDA8 $\mathrm{O}_{3}$, however, indicate widespread increases in Figure 2g,h. The differences in the $\mathrm{PM}_{2.5}$ and $\mathrm{O}_{3}$ in Figure 2 could be potentially driven by the meteorological variations and long-term emission changes. Figure 3 plots the mean for each episode for temperature, wind speed, $\mathrm{PM}_{2.5}$, and $\mathrm{O}_{3}$. The meteorological factors in 2020 are generally within the spread of the past years' variability. In Figure $3 b, c$, the $\mathrm{PM}_{2.5}$ and wind speed are clearly inversely correlated during 2015-2020 in Episode 2 (blue dots), suggesting that meteorology is possibly one of the contributing factors to the changes in $\mathrm{PM}_{2.5}$. A similar inverse correlated pattern (with much smaller variability) during 2015-2019 is shown in Episode 1, while the $\mathrm{PM}_{2.5}$ in 2020 exhibits a notable further decrease. This further decrease could result from emission reductions from the COVID-19 lockdown. The $\mathrm{O}_{3}$ and meteorological factors show less association. 

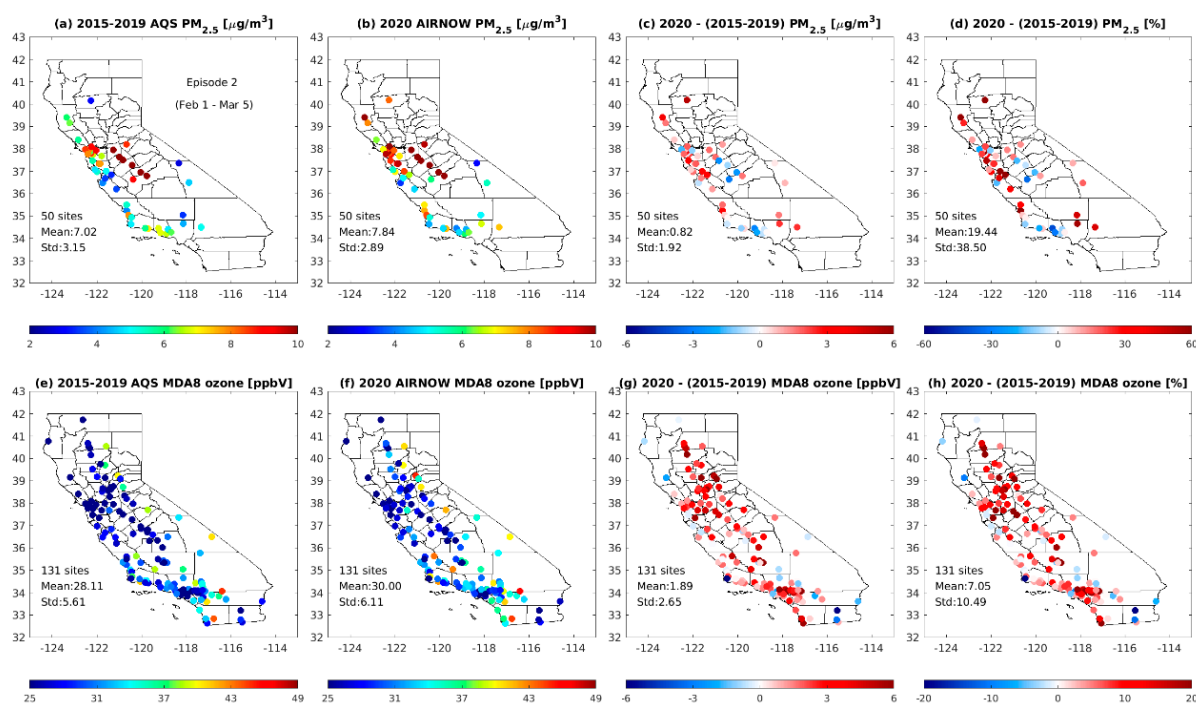

Figure 2. The Episode 2 (1 February-5 March) episode-average surface concentrations of $\mathrm{PM}_{2.5}$ and MDA8 $\mathrm{O}_{3}$ : (a) historical $\mathrm{PM}_{2.5}$, (b) normal $\mathrm{PM}_{2.5}$, (c) normal minus historical $\mathrm{PM}_{2.5}$, (d) similar to (c) but in percentage, (e) historical $\mathrm{MDA}_{8} \mathrm{O}_{3}$, (f) normal MDA8 $\mathrm{O}_{3}$, (g) normal minus historical MDA8 $\mathrm{O}_{3}$, (h) similar to (g) but in percentage.
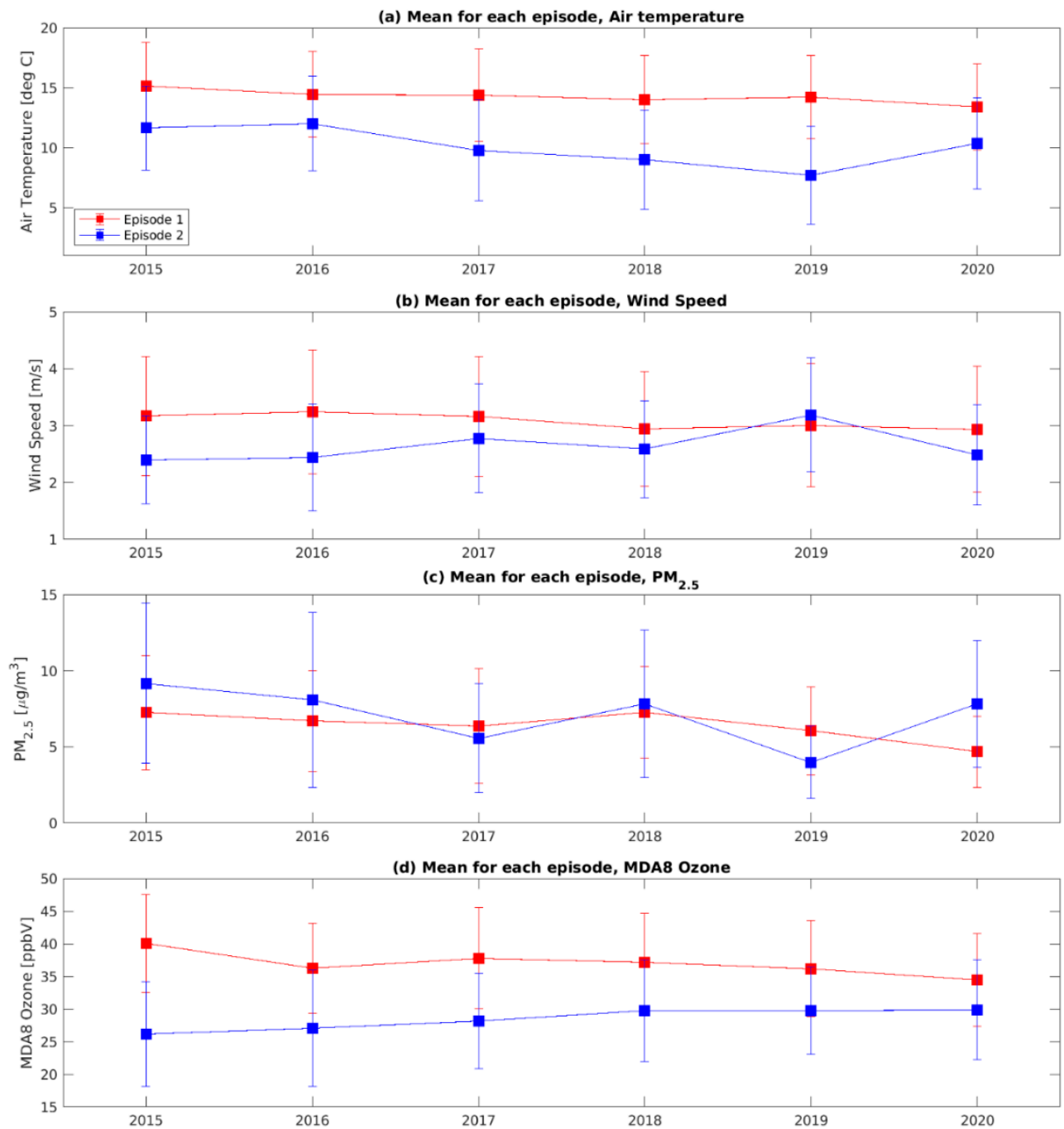

Figure 3. The mean for each episode: (a) air temperature, (b) wind speed, (c) $\mathrm{PM}_{2.5}$, and (d) $\mathrm{O}_{3}$. 


\subsection{Potential Health Impacts Resulting from the Change in Air Quality}

As depicted in Table 2, if the $\mathrm{PM}_{2.5}$ reductions during the lockdown could persist over a year, it could lead to a substantial prevented premature mortality annually, ranging from 3820 (95\% CI: 2590-5040) cases to 8570 (95\% CI: 4310-12700) cases, depending on which C-R relationship was being used to obtain the estimates. Predominant $\mathrm{MDA} 8 \mathrm{O}_{3}$ reductions during the lockdown could lead to 150 (95\% CI: 81-220) cases to 332 (95\% CI: 227-435) cases of prevented premature mortality. Assuming that the $\mathrm{PM}_{2.5}$ changes during the Episode 2 persist over a year, however, it could generally lead to increased numbers of premature deaths. The numbers range from 1480 (95\% CI: 1000-1970) cases to 3390 (95\% CI: 1680-5110) cases of additional premature deaths attributable to $\mathrm{PM}_{2.5}$. The estimates attributable to $\mathrm{O}_{3}$ are from 121 (95\% CI: 65-177) cases to 267 (95\% CI: 183-351) cases. The $\mathrm{PM}_{2.5}$-attributable health impact results in Episode 1 have a greater magnitude than those in Episode 2, while the $\mathrm{O}_{3}$-attributable results are comparable and opposite in magnitude between Episode 1 and Episode 2.

Table 2. Estimates of the prevented premature mortality attributable to the changes in the concentrations of $\mathrm{PM}_{2.5}$ and $\mathrm{MDA}_{8} \mathrm{O}_{3}$ in California.

\begin{tabular}{|c|c|c|c|}
\hline Species & Epidemiological Reference & \multicolumn{2}{|c|}{ Prevented Premature Mortality in California } \\
\hline \multirow{2}{*}{$\mathrm{PM}_{2.5}$} & Krewski et al. [6] & $\begin{array}{c}3820 \\
(2590,5040)\end{array}$ & $\begin{array}{c}-1480 \\
(-1000,-1970)\end{array}$ \\
\hline & Woodruff et al. [8] & $\begin{array}{c}22 \\
(8,35) \\
\end{array}$ & $\begin{array}{c}-8 \\
(-3,-12)\end{array}$ \\
\hline Ozone & Bell et al. [9] & $\begin{array}{c}235 \\
(112,358)\end{array}$ & $\begin{array}{c}-189 \\
(-90,-288)\end{array}$ \\
\hline
\end{tabular}

Notation: In the 3rd and 4th columns, (1) the numbers in parentheses represent 95\% confidence intervals, which result from a full Monte-Carlo analysis performed by BenMAP, by randomly sampling an uncertainty distribution around the C-R coefficients; (2) positive values indicate the number of premature deaths prevented because of air quality improvement, while the negative values indicate an increase in the number of premature deaths due to air quality exacerbation.

Similarly, Figure 4 depicts the estimations of prevented premature mortality attributable to $\mathrm{PM}_{2.5}$ and $\mathrm{O}_{3}$ during each episode, but at two large metropolitan areas and San Joaquin Valley. The health impact estimates vary largely across different regions or time periods. For instance, during the lockdown time period, the $\mathrm{PM}_{2.5}$-attributable prevented premature deaths in LA (2119 cases) are notably larger than those in SF (455 cases), resulting from larger reductions in the $\mathrm{PM}_{2.5}$ concentrations and the bigger population size in LA. During the normal time period, however, the difference in the $\mathrm{PM}_{2.5}$-attributable health impact estimates between LA and SF (533 and 368 cases) becomes much smaller, as the $\mathrm{PM}_{2.5}$ in both areas exhibits a mixed change in increase and decrease. Additionally, the magnitudes of the $\mathrm{PM}_{2.5}$-attributable health impact results are clearly larger in Episode 1 than Episode 2 in the LA and SJV areas; the magnitudes of the $\mathrm{O}_{3}$-attributable results are close to equal in Episode 1 and Episode 2. Based on the analyses, COVID-19's air quality impact is most significant for $\mathrm{PM}_{2.5}$, and greater in the LA and SJV areas; COVID-19's impact on $\mathrm{O}_{3}$ is very uncertain. 

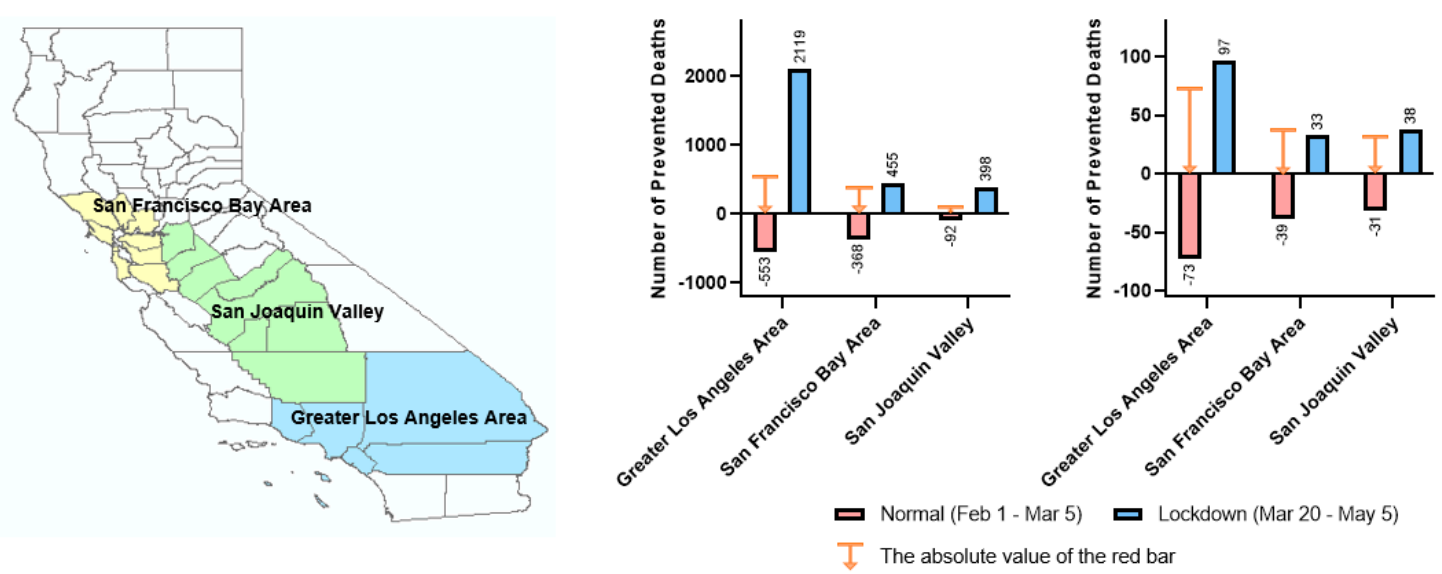

Figure 4. (a) Map of the locations of two metropolitan areas and San Joaquin Valley, and (b) estimates of the prevented premature mortality resulting from the changes in concentrations of $\mathrm{PM}_{2.5}$ and $\mathrm{MDA}_{8} \mathrm{O}_{3}$.

\subsection{Dramatic Declines in Public Transit Demand}

One of primary sources of anthropogenic emissions is transportation in large urban areas. Dramatic declines in public transit demand allow us to assume a significant reduction in the vehicle miles traveled and emissions. Figure 5 depicts the change in public transit demand in different selective days. In both LA and SF, the demand on a typical normal Monday exhibits clearly morning and afternoon peaks (i.e., "rush hour"). On 9 March, before the stay-at-home order was implemented, the demand was slightly lower than the normal condition. While, on 23 March, when the lockdown was applied, the demand showed dramatic declines, at $\sim 80 \%$ and $\sim 90 \%$ lower than the peak demand on a normal Monday in LA and SF, respectively. These substantial declines in demand could partly result from reduced public transit service time, frequency, and lines; another cause could be that less people choose public transit out of fear of the virus spreading.
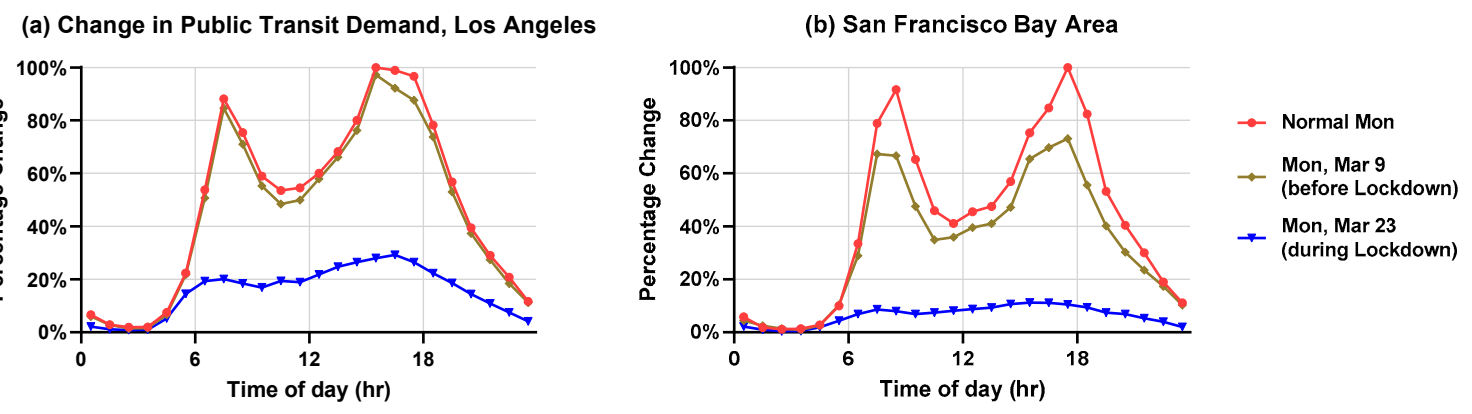

Figure 5. Change in public transit demand in two metropolitan areas. Data source: Transit app [26]. Note: "public transit demand" here refers to the frequency of Transit app opens; it does not represent transit ridership. This could become a potential limitation. Normal usage is defined as the projected use of the app based on last year's numbers (adjusted for annual growth) [26].

\subsection{Implications of the Air Quality Change on Future Passenger Travel, Freight, and Energy Use}

The traffic reductions and air quality improvements come from a way no one would like, and the changes are not sustainable. Nevertheless, the pandemic provides an opportunity to exhibit how substantially human behavior can impact on air quality. The lockdown and changing behavior bring down not only the emissions of air pollutants but also of greenhouse gases (GHGs). Thus, to address both the pandemic and climate change issues, better strategies are needed to affect human behavior. There are several implications can be drawn from the analyses in this study: 
(1) Ensuring safer shared mobility. Restricted use of public transit has been applied during the pandemic to comply with the social distancing guidelines. In the post-pandemic period, people may have less confidence on public transportation, and shift to private car use. However, single-driver private car use is not a sustainable transportation mode. As depicted in Figure 6, single-driver travels represent more than 70\% of commuting travels. In 2018, California set a goal of adopting five million zero-emission cars by 2030 [29]. However, the increased numbers of electric vehicles on the road may still lead to congestion and increase the emissions from conventional vehicles with internal combustion engines (ICE) [30,31]. Shared mobility, including both public transit and carpooling, is needed to greatly reduce the number of vehicles and carbon emissions [32]. Hence, it is important to ensure safer and healthier shared travel to improve consumers' confidence on return to sharing. Shared mobility is also essential to underserved populations or those experiencing economic hardship due to the pandemic. A survey of 25,000 individuals still riding public transit during COVID-19 suggests that the riders are mostly female, people of color, and low-income workers [33]. Thus, addressing the equity issues and allocating funds to build better public transit are critically important.

(2) Increased adoption of telecommuting. The adoption rate of telecommuting is $\sim 5 \%$ during the normal time, as depicted in Figure 6. The rate is expected to substantially increase during the pandemic, and the air quality improvement (in Figure 1) should in part result from the adoption of telecommuting and the associated travel reduction. Telecommuting, which eliminate a commute, can lower energy and fuel use, reduce emissions and congestion, and bring about time and travel cost savings. It also gives the employees more flexibility in balancing work and personal obligations, and saves office expenses for employers. There could be certain downsides of working from home; some people may easily get distracted or feel a bit isolated. Thus, it is important to weigh the pros and cons when considering a telecommuting job. Figure 7 shows the telecommuting status by industry (data available only for the U.S.). Some industries may consider increasing the adoption of telecommuting, such as professionals, sales, marketing, and information technology jobs.

(3) Automation in the freight sector. Due to the pandemic, more people may shift from shopping at malls/stores to teleshopping in the future. The truck activity in California was down only $\sim 8 \%$ in April (i.e., the lockdown time period), compared to the normal demand in February and early March this year [34]. Hence, the future shifting to teleshopping may increase freight logistics and delivery. Freight trucks account for only small portion of the vehicle miles traveled (VMT), however, they make up 25\% of the $\mathrm{PM}_{2.5}$ emissions and $~ 50 \%$ of the $\mathrm{NO}_{\mathrm{x}}$ emissions, as depicted in Figure 9 [35-37]. Automation in the freight sector can help to improve the efficiency, reduce emissions, and reduce human contact. In addition, electrifying trucks or autonomous trucks is needed to further reduce energy use and emissions.

(4) Cleaner energy transition. In addition to the adoption of five million electric cars [29], California set plan to accelerate zero-emission truck markets [38]. Instead of burning gasoline or diesel, these new cars and trucks would run on electricity, which should be largely generated from renewable sources such as solar, wind, geo-thermal, and hydropower. As depicted in Figure 8, California is ahead of the nation in adopting cleaner energy. Coal has been almost phased out, and solar and geo-thermal contribute to $13.8 \%$ and $6 \%$ of the total generation in California (vis-à-vis $1.5 \%$ and $0.4 \%$ for the national average). Emission rates for GHGs from electricity generation in California are less than half of the national average, as shown in Figure 10. Thus, in order to maximize the air quality improvement and mitigate climate change, the electrification of passenger travel and freight sectors in the future also require the continuing strong de-carbonization of the power sector.

Future studies can be conducted to investigate the air quality and health impacts of the environmental initiatives mentioned above. We have performed several assessments of similar control strategies for transportation emissions. For instance, electrifying 95\% of passenger vehicles would lead to 1950 prevented early deaths annually in California [39]; fleet turnover with maintaining 
stringent emission standards for heavy-duty trucks would lead to 1120 prevented early deaths [25]. In this study, air quality improvements during the lockdown would lead to 3820 prevented early deaths if they persisted for a whole year (note: the estimation could not be solely attributable to COVID-19). It is not clear how COVID-19 could accelerate or hinder the initiatives. On 25 June 2020, California regulators approved a first-of-its-kind rule on electric trucks and vans, requiring at least $40 \%$ of tractor trailers, $55 \%$ of smaller trucks, and $75 \%$ of delivery trucks and vans sold in California to be zero-emission by 2035; the rule would not take effect until $2024[38,40]$. It might be reasonable that corporations may find it harder to comply with more stringent emission control policies, due to the temporary economic downturn tied to the viral outbreak. Part of the emergency funding (e.g., the Coronavirus Aid, Relief, and Economic Security (CARES) Act) can be used to build more sustainable transportation infrastructure.

Promoting the adoption of zero-emission cars and freight trucks represent California's efforts in curbing emissions and air pollution from the technology and policy perspectives, whether by choosing public transit, ride sharing, or telecommuting - these are more related to human behavior. The technology, policy, and behavior impacting pathways are interrelated, and future substantial reductions in emissions require a combination of the different impacting pathways.

\section{Means of Commuting to Work}

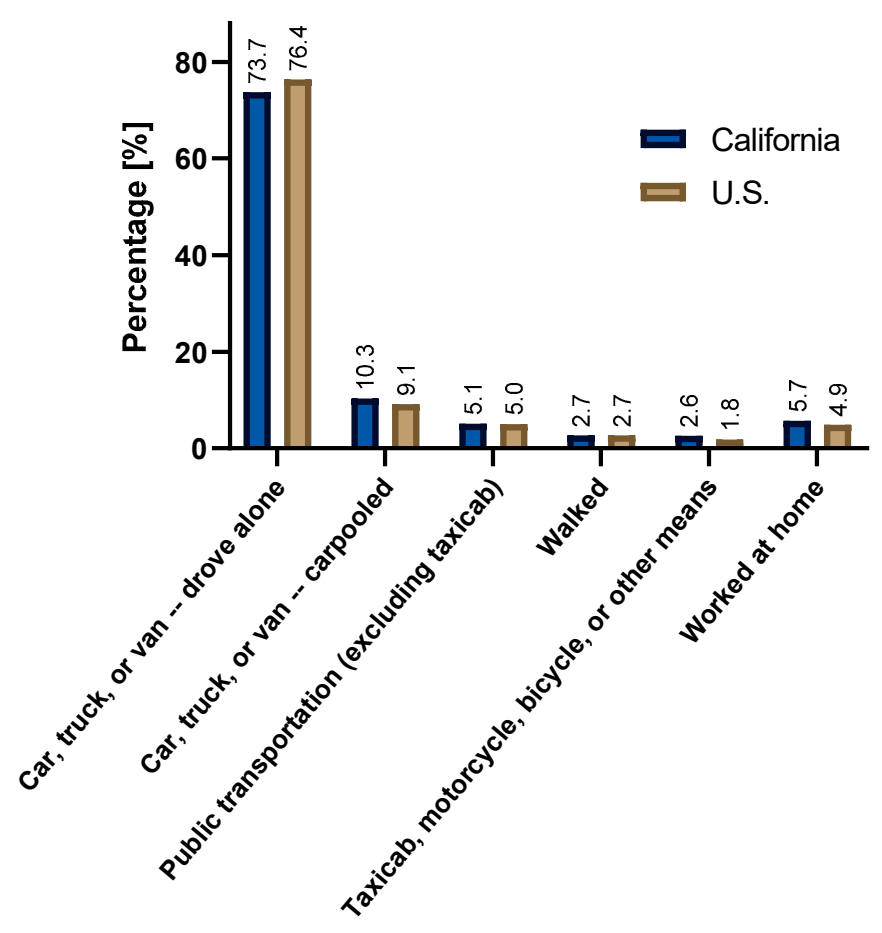

Figure 6. Means of commuting to work in the U.S. and California. Data source: 2018 American Community Survey (ACS) 5-year estimates [27]. 


\section{Working from home by Industry}

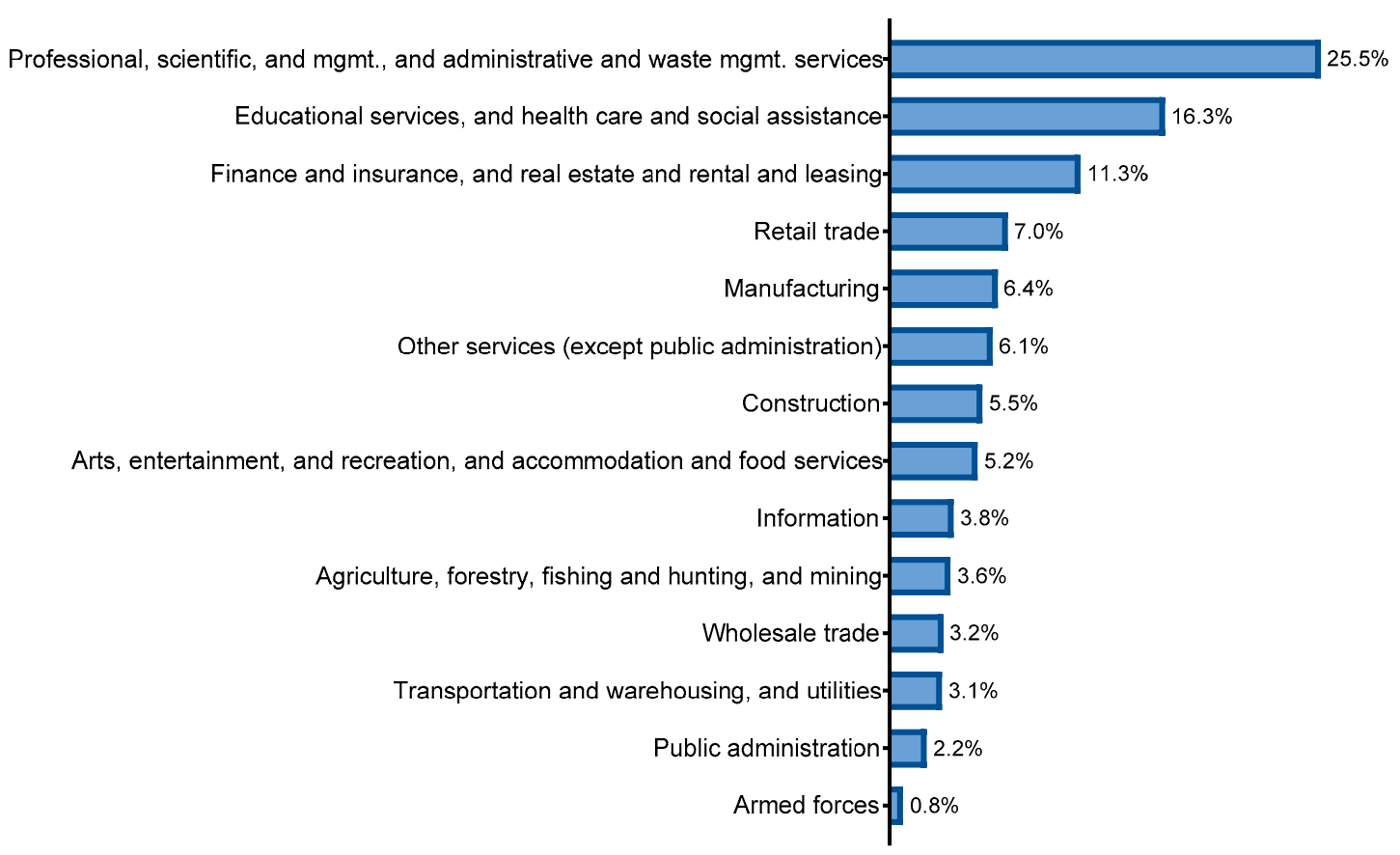

Figure 7. Telecommuting status by industry for the U.S. employees. Data source: 2018 American Community Survey (ACS), 5-year Estimates [27].

\section{Electricity Generation Resource Mix}

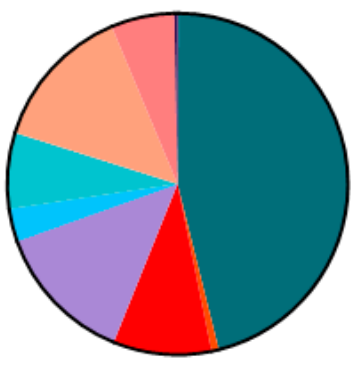

California

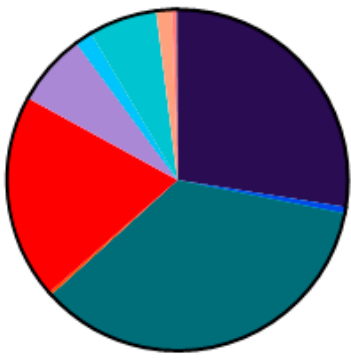

U.S.

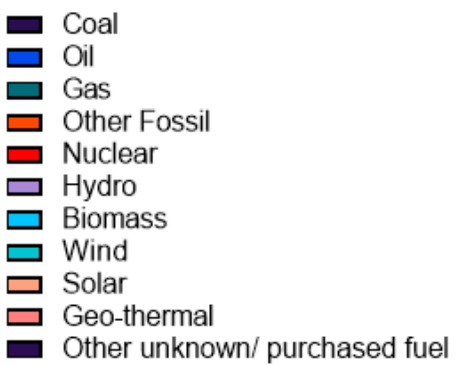

Other unknown/ purchased fuel

Figure 8. Electricity generation resource mix in the U.S. and California. Data source: U.S. EPA Emissions and Generation Resource Integrated Database (eGRID2018) [26]. 
California 2014 Mobile Emissions [\%]

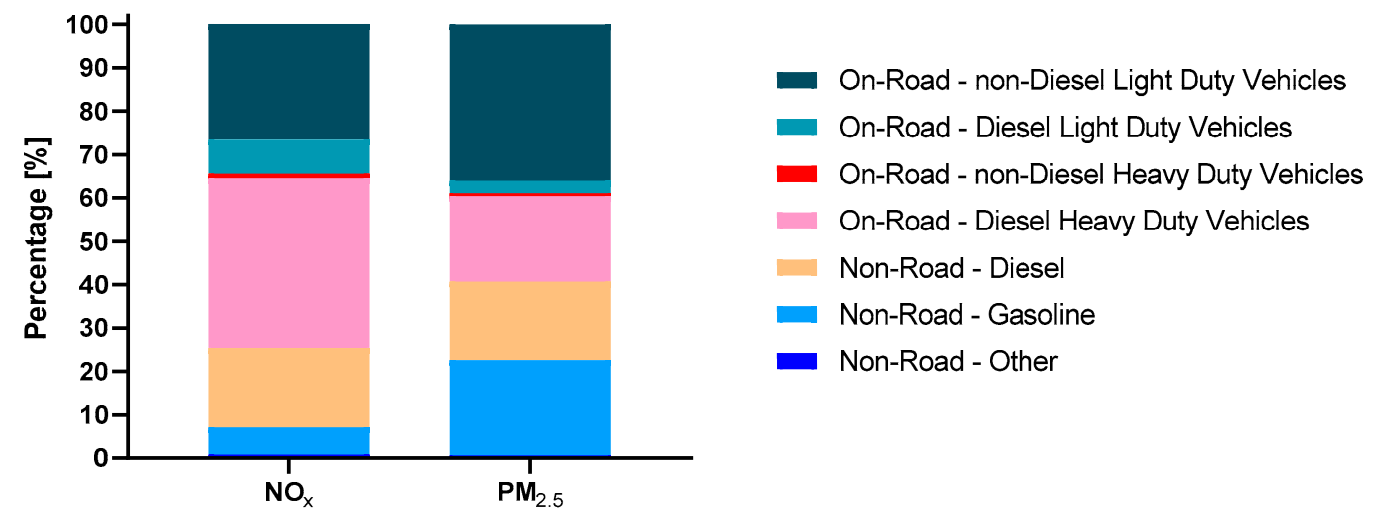

Figure 9. Mobile source contributions to emissions of $\mathrm{NO}_{\mathrm{x}}$ and $\mathrm{PM}_{2.5}$ in California. Data source: U.S. EPA 2014 National Emission Inventory (NEI) [35].

\section{Total Output Emission Rates}

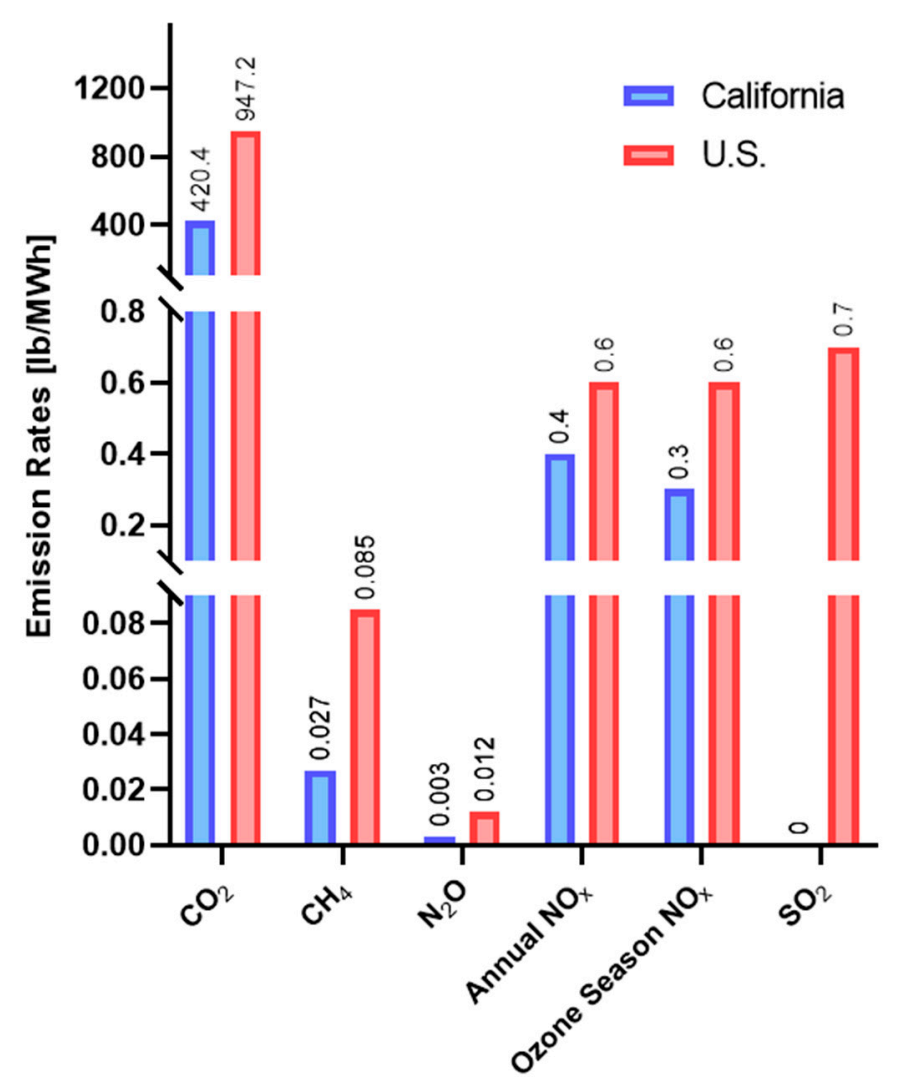

Figure 10. Total output emission rates from electricity generation in the U.S. and California. Data source: U.S. EPA Emissions and Generation Resource Integrated Database (eGRID2018) [26].

\subsection{Uncertainties and Limitations}

The air quality analyses in this study indicate clear reductions in $\mathrm{PM}_{2.5}$ and $\mathrm{O}_{3}$, and we have seen large reductions in passenger travel and a slight decrease of trucking freight. However, the exact source contributions to the air quality reductions require further data collection from each emission source sector. The accurate characterization of the emission changes would be not easy, because the changes are not only from total emission amounts but also the daily variation profiles (e.g., in Figure 5). Future studies can be performed to better explain the air quality changes by combining improved 
emission inventories and chemical transport model [1]. Another technical limitation is that the direct comparison of air quality during the COVID-19 with previous years (2015-2019) (e.g., Episode 1 in Figure 1) cannot exclude influences from long-term trends in air quality changes. As shown in Figures 2 and 3, there is a long-term trend in air quality in Episode 2 (February-5 March), which could be due to meteorological variations and long-term emission changes. This is particularly concerning for $\mathrm{O}_{3}$, which has an overall increasing trend in Episode 2, suggesting that not accounting for the long-term trend in air quality could mainly bias the estimated air quality changes due to COVID-19.

It should be noted that the health impact estimates in this study have significant uncertainties. First, for $\mathrm{PM}_{2.5}$, the epidemiological studies adopted here include assessment for long-term exposure, which is mainly estimated based on the annual average levels and may not be suitable enough for health impact assessment of short-term exposure. Hence, the estimated 3820-8570 prevented premature deaths in California are resulted from 1-3 $\mu \mathrm{g} \mathrm{m}^{-3}$ reductions in $\mathrm{PM}_{2.5}$ persisting over a year, not the short period of about 45 days. For $\mathrm{O}_{3}$, the $\mathrm{C}$ - $\mathrm{R}$ functions used here are for short-term exposure (or acute effects), since the cited epidemiological studies all estimated effects based on times-series analyses of daily $\mathrm{O}_{3}$ exposures. Second, the health impact attributable to air quality changes is strongly affected by the spatial distributions of both population density and ambient pollutant concentrations, while human behaviors changed significantly during the lockdown period. Supposedly, people spend more time at home than usual, and they reduce the time spent in commuting, recreation, and office places. This issue would raise another significant limitation using the previous C-R functions. Third, the air monitoring stations are mostly concentrated in the southwestern part of California. The VNA method may not be able to ensure the representativeness of data in areas with only a few observations. Four, the pandemic could impact on many other aspects of human health, such as placing stress on people's lives and on the health care system [41,42]. These impacts are more difficult to quantify.

Author Contributions: Conceptualization, methodology, and writing, S.P. and H.O.G.; formal analysis, S.P., J.J., X.H., A.R., Y.C., and H.O.G.; visualization, J.J. and Z.L. All authors have read and agreed to the published version of the manuscript.

Funding: This research was funded by the United States Department of Transportation (U.S. DOT) Center for Transportation, Environment, and Community Health (CTECH), and the Research Start-up Fund of NUIST. And the APC was funded by the CTECH and the Research Start-up Fund of NUIST.

Acknowledgments: The authors thank Jonathan Scheff for providing the transit demand data. The authors acknowledge the free use of the U.S. EPA AirNow, AQS, NEI, and eGRID data, the U.S. Census ACS data, and Iowa State University ASOS data. The views expressed in this paper are those of the authors and do not necessarily represent the views of any agency, institution, or organization. The authors appreciate the anonymous reviewers who helped improve quality of this paper greatly.

Conflicts of Interest: The authors declare no conflict of interest.

\section{References}

1. Huang, X.; Ding, A.J.; Gao, J.; Zheng, B.; Zhou, D.; Qi, X.; Tang, R.; Wang, J.; Ren, C.; Nie, W.; et al. Enhanced secondary pollution offset reduction of primary emissions during COVID-19 lockdown in China. Natl. Sci. Rev. 2020, nwaa137. [CrossRef]

2. Bauwens, M.; Compernolle, S.; Stavrakou, T.; Müller, J.-F.; Van Gent, J.; Eskes, H.; Levelt, P.F.; Van Der, A.R.; Veefkind, J.P.; Vlietinck, J.; et al. Impact of Coronavirus Outbreak on NO 2 Pollution Assessed Using TROPOMI and OMI Observations. Geophys. Res. Lett. 2020, 47, e2020GL087978. [CrossRef]

3. Shi, X.; Brasseur, G.P. The Response in Air Quality to the Reduction of Chinese Economic Activities During the COVID-19 Outbreak. Geophys. Res. Lett. 2020, 47, e2020GL088070. [CrossRef] [PubMed]

4. Le Quéré, C.; Jackson, R.B.; Jones, M.W.; Smith, A.J.P.; Abernethy, S.; Andrew, R.M.; De-Gol, A.J.; Willis, D.R.; Shan, Y.; Canadell, J.G.; et al. Temporary reduction in daily global CO2 emissions during the COVID-19 forced confinement. Nat. Clim. Chang. 2020, 1-7. [CrossRef]

5. Zhao, Y.; Zhang, K.; Xu, X.; Shen, H.; Zhu, X.; Zhang, Y.; Hu, Y.; Shen, G. Substantial Changes in Nitrogen Dioxide and Ozone after Excluding Meteorological Impacts during the COVID-19 Outbreak in Mainland China. Environ. Sci. Technol. Lett. 2020, 7, 402-408. [CrossRef] 
6. $\quad$ Krewski, D.; Jerrett, M.; Burnett, R.T.; Ma, R.; Hughes, E.; Shi, Y.; Turner, M.C.; Pope, C.A.; Thurston, G.; Calle, E.E.; et al. Extended Follow-Up and Spatial Analysis of the American Cancer Society Study Linking Particulate air pollution And Mortality; No. 140; Health Effects Institute: Cambridge, MA, USA, 2009.

7. Lepeule, J.; Laden, F.; Dockery, D.W.; Schwartz, J. Chronic Exposure to Fine Particles and Mortality: An Extended Follow-up of the Harvard Six Cities Study from 1974 to 2009. Environ. Health Perspect. 2012, 120, 965-970. [CrossRef] [PubMed]

8. Woodruff, T.J.; Grillo, J.; Schoendorf, K.C. The relationship between selected causes of postneonatal infant mortality and particulate air pollution in the United States. Environ. Health Perspect. 1997, 105, 608-612. [CrossRef]

9. Bell, M.; Dominici, F.; Samet, J.M. A Meta-Analysis of Time-Series Studies of Ozone and Mortality With Comparison to the National Morbidity, Mortality, and Air Pollution Study. Epidemiology 2005, 16, 436-445. [CrossRef] [PubMed]

10. Levy, J.I.; Chemerynski, S.M.; Sarnat, J.A. Ozone exposure and mortality: An empiric bayes metaregression analysis. Epidemiology 2005, 16, 458-468. [CrossRef]

11. Zanobetti, A.; Schwartz, J. Mortality Displacement in the Association of Ozone with Mortality. Am. J. Respir. Crit. Care Med. 2008, 177, 184-189. [CrossRef]

12. U.S. EPA, Nonattainment Areas for Criteria Pollutants (Green Book). 2020. Available online: https: //www.epa.gov/green-book (accessed on 31 May 2020).

13. Newsom, G. Executive Order N-33-20. Available online: https://www.gov.ca.gov/wp-content/uploads/2020/ 03/3.19.20-attested-EO-N-33-20-COVID-19-HEALTH-ORDER.pdf (accessed on 20 March 2020).

14. Newsom, G. Executive Order N-60-20. Available online: https://www.gov.ca.gov/wp-content/uploads/2020/ 05/5.4.20-EO-N-60-20.pdf (accessed on 5 May 2020).

15. U.S. EPA, AirNow. 2020. Available online: https://www.airnow.gov/ (accessed on 10 May 2020).

16. U.S. EPA, Air Quality System (AQS). 2020. Available online: https://www.epa.gov/aqs (accessed on 10 May 2020).

17. Chai, T.; Kim, H.; Lee, P.; Tong, D.; Pan, L.; Tang, Y.; Huang, J.; McQueen, J.; Tsidulko, M.; Stajner, I. Evaluation of the United States National Air Quality Forecast Capability experimental real-time predictions in 2010 using Air Quality System ozone and NO2 measurements. Geosci. Model Dev. 2013, 6, 1831-1850. [CrossRef]

18. Williams, R.; Nash, G.D.; Hagler, K.; Benedict, I.; MacGregor, B.; Seay, M.; Lawrence, T.D. Peer Review and Supporting Literature Review of Air Sensor Technology Performance Targets; U.S. Environmental Protection Agency: Washington, DC, USA, 2018.

19. Sacks, J.D.; Lloyd, J.M.; Zhu, Y.; Anderton, J.; Jang, C.J.; Hubbell, B.; Fann, N. The Environmental Benefits Mapping and Analysis Program Community Edition (BenMAP-CE): A tool to estimate the health and economic benefits of reducing air pollution. Environ. Model. Soft. 2018, 104, 118-129. [CrossRef]

20. Sacks, J.D.; Fann, N.; Gumy, S.; Kim, I.; Ruggeri, G.; Mudu, P. Quantifying the Public Health Benefits of Reducing Air Pollution: Critically Assessing the Features and Capabilities of WHO's AirQ+ and U.S. EPA's Environmental Benefits Mapping and Analysis Program-Community Edition (BenMAP-CE). Atmosphere 2020, 11, 516. [CrossRef] [PubMed]

21. Davidson, K.F.; Fann, N.; Zawacki, M.; Fulcher, C.; Baker, K.R. The recent and future health burden of the U.S. mobile sector apportioned by source. Environ. Res. Lett. 2020, 15, 075009. [CrossRef]

22. U.S. EPA, Regulatory Impact Analysis for the Final Revisions to the National Ambient Air Quality Standards for Particulate Matter. 2012. Available online: https://www3.epa.gov/ttnecas1/regdata/RIAs/finalria.pdf (accessed on 10 May 2020).

23. U.S. EPA. Environmental Benefits Mapping and Analysis Program: Community Edition (BenMAP-CE) User Manual and Appendices; U.S. EPA: Research Triangle Park, NC, USA, 2017.

24. Pan, S.; Roy, A.; Choi, Y.; Eslami, E.; Thomas, S.; Jiang, X.; Gao, H. Potential impacts of electric vehicles on air quality and health endpoints in the Greater Houston Area in 2040. Atmos. Environ. 2019, 207, 38-51. [CrossRef]

25. Pan, S.; Roy, A.; Choi, Y.; Sun, S.; Gao, H. The air quality and health impacts of projected long-haul truck and rail freight transportation in the United States in 2050. Environ. Int. 2019, 130, 104922. [CrossRef]

26. Transit app. How Coronavirus Is Disrupting Public Transit: Change in Demand. 2020. Available online: https://transitapp.com/coronavirus (accessed on 14 May 2020). 
27. U.S. Census, 2018 American Community Survey, 5-Year Estimates. 2019. Available online: https://www. census.gov/programs-surveys/acs/data.html (accessed on 14 May 2020).

28. U.S. EPA, Emissions and Generation Resource Integrated Database (eGRID), eGRID2018. 2020. Available online: https://www.epa.gov/energy/emissions-generation-resource-integrated-database-egrid (accessed on 9 March 2020).

29. Fisher, R.; Tang, M.; Le, T.; Yee, D.; White, K. Accelerating beyond Early Adopters to Achieve Equitable and Widespread Electric Vehicle Use in the San Francisco Bay Area. World Electr. Veh. J. 2019, 11, 3. [CrossRef]

30. Kelly, F.J.; Zhu, T. Transport solutions for cleaner air. Science 2016, 352, 934-936. [CrossRef]

31. Peng, W.; Yang, J.; Lu, X.; Mauzerall, D.L. Potential co-benefits of electrification for air quality, health, and CO2 mitigation in 2030 China. Appl. Energy 2018, 218, 511-519. [CrossRef]

32. Fulton, L.; Mason, J.; Meroux, D. Three Revolutions in Urban Transportation: How to Achieve the Full Potential of Vehicle Electrification, Automation and Shared Mobility in Urban Transportation Systems Around the World by 2050; Institute of Transportation Studies at UC Davis and Institute for Transportation \& Development Policy (ITDP): New York, NY, USA, 2017.

33. Transit app. Who's Left Riding Public Transit? 2020. Available online: https://medium.com/transit-app/ whos-left-riding-public-transit-hint-it-s-not-white-people-d43695b3974a (accessed on 14 May 2020).

34. ATRI (American Transportation Research Institute). New Data Show COVID-19 Impacts on the Trucking Industry; American Transportation Research Institute: Arlington, VA, USA, 2020. Available online: https: //truckingresearch.org/2020/04/22/new-data-show-covid-19-impacts-on-the-trucking-industry/ (accessed on 28 April 2020).

35. U.S. EPA, 2014 National Emission Inventory Report: Source Contributions. 2018. Available online: https://gispub.epa.gov/neireport/2014/ (accessed on 20 May 2020).

36. Liu, L.; Hwang, T.; Lee, S.; Ouyang, Y.; Lee, B.; Smith, S.J.; Yan, F.; Daenzer, K.; Bond, T.C. Emission Projections for Long-Haul Freight Trucks and Rail in the United States through 2050. Environ. Sci. Technol. 2015, 49, 11569-11576. [CrossRef] [PubMed]

37. Liu, L.; Hwang, T.; Lee, S.; Ouyang, Y.; Lee, B.; Smith, S.J.; Tessum, C.W.; Marshall, J.D.; Yan, F.; Daenzer, K.; et al. Health and climate impacts of future United States land freight modelled with global-to-urban models. Nat. Sustain. 2019, 2, 105-112. [CrossRef]

38. CARB (California Air Resources Board), Advanced Clean Trucks Fact Sheet: Accelerating Zero-Emission Truck Markets. 2020. Available online: https://ww2.arb.ca.gov/resources/fact-sheets/advanced-clean-trucksfact-sheet (accessed on 25 June 2020).

39. Pan, S.; Fulton, L.M.; Roy, A.; Jung, J.; Choi, Y.; Gao, H.O. Energy, Air Quality, and Health Impacts of Future Mobility; Washington, DC, USA, 2020; Submitted.

40. CBS News. California Approves First-Of-Its-Kind Rule on Electric Trucks and Vans. 2020. Available online: https://www.cbsnews.com/news/california-approves-first-of-its-kind-rule-to-mandatezero-emission-truck-and-van-sales/ (accessed on 25 June 2020).

41. Baumgartner, J. Cited in "China's Efforts to Control Coronavirus Lead to Less Air Pollution". NPR. 11 March 2020. Available online: https://www.npr.org/2020/03/11/814353594/chinas-efforts-to-control-coronavirusleads-to-less-air-pollution (accessed on 28 March 2020).

42. Torales, J.; O'Higgins, M.; Castaldelli-Maia, J.M.; Ventriglio, A. The outbreak of COVID-19 coronavirus and its impact on global mental health. Int. J. Soc. Psychiatry 2020, 31, 0020764020915212. [CrossRef] [PubMed]

(C) 2020 by the authors. Licensee MDPI, Basel, Switzerland. This article is an open access article distributed under the terms and conditions of the Creative Commons Attribution (CC BY) license (http://creativecommons.org/licenses/by/4.0/). 